University of Windsor

Scholarship at UWindsor

\title{
3-2009
}

\section{Personality and motivations associated with Facebook use}

\author{
Craig Ross \\ University of Windsor \\ Emily Orr \\ University of Windsor \\ Mia Sisic \\ University of Windsor \\ Jaime Michelle Arseneault \\ Mary G Simmering \\ University of Windsor
}

See next page for additional authors

Follow this and additional works at: https://scholar.uwindsor.ca/psychologypub

Part of the Psychology Commons

\section{Recommended Citation}

Ross, Craig; Orr, Emily; Sisic, Mia; Arseneault, Jaime Michelle; Simmering, Mary G; and Orr, Robert. (2009). Personality and motivations associated with Facebook use. Computers in Human Behavior, 25 (2), 578-586.

https://scholar.uwindsor.ca/psychologypub/31

This Article is brought to you for free and open access by the Department of Psychology at Scholarship at UWindsor. It has been accepted for inclusion in Psychology Publications by an authorized administrator of Scholarship at UWindsor. For more information, please contact scholarship@uwindsor.ca. 


\section{Authors}

Craig Ross, Emily Orr, Mia Sisic, Jaime Michelle Arseneault, Mary G Simmering, and Robert Orr 


\section{Personality and motivations associated with Facebook use}

Craig Ross *, Emily S. Orr, Mia Sisic, Jaime M. Arseneault, Mary G. Simmering, R. Robert Orr

Department of Psychology, University of Windsor, 173-2 Chrysler Hall South, 401 Sunset Avenue, Windsor, ON, Canada N9B 3P4

Keywords: Computer Mediated Communication (CMC) Personality Internet Use Facebook Five-Factor Model NEO-PI-R

First published in Computers in Human Behavior 25 (2009) 578-586

http://dx.doi.org/10.1016/j.chb.2008.12.024

\section{Personality correlates and competency factors associated with Facebook use}

The purpose of the present study was to examine the nature of Facebook use in an undergraduate sample and explore the personality and competency factors that influence its use. Assessment of personality over the past two decades has revealed that personality can be characterized by a series of five dimensions (McCrae, 1992). This has resulted in a Five-Factor Model (FFM) of personality that has come to pervade personality research. Nonetheless, some test developers have created personality assessment tools that neglect one or more of these dimensions (e.g., the Eysenck Personality Questionnaire lacks a scale assessing Openness to Experience; Goldberg \& Rosolack, 1994). Costa and McCrae (1992a, 1992b) specifically created the NEO Personality Inventory-Revised (NEO-PI-R) to assess the five factors that have appeared consistently throughout the personality assessment literature. The success of the NEOPI-R model in assessing personality and behaviors in the "real" world provides us with a solid framework with which to examine behaviors in the "virtual" world. Thus, in the present study, personality will be defined in terms of the Five-Factor Model and assessed with the NEO-PI-R.

The modern Internet has been presented as a combination of all previous communication technologies (Bargh \& McKenna, 2004). Capable of simultaneously broadcasting vast amounts of information to a large number of individuals (much like television), the Internet can also provide an intimate venue for interpersonal conversation (much like the telephone). With these capabilities, the Internet has the potential to create a fundamental shift in how people communicate.

One of the consequences of the change in communication practices has been the introduction of Social Networking Sites (SNSs). The use of an SNS can allow an individual to find others with similar interests, whether it be for romantic or social purposes (McKenna, Katelyn, Green, Glenson, \& Marci, 2002). The other major use of SNSs is to maintain pre-existing social connections (Ellison, Steinfield, \& Lampe, 2007). Research by McKenna and colleagues (2002) suggests that the types of interactions which are made possible through an SNS may actually result in a stronger relationship than might be possible through face-to-face methods. One reason for the deeper relationships observed through online activities is that a different set of rules govern online interactions. For example, Tidwell and Walther 
(2002) observed that online interactions generated more self-disclosures and fostered deeper personal questions than did face-to-face conversations. Without the types of restrictions that govern typical faceto-face conversations, those engaging in online conversations were more able to ask deep personal questions (e.g., asking about a person's sexual orientation) without offending their conversation partner (Tidwell \& Walther, 2002).

Because of the inherently interpersonal nature of an SNS, many relationships formed online eventually result in realworld contact. The process of meeting an online contact is often marked by a series of stages in which trust and comfort are built (McKenna et al., 2002). The majority of the SNSs demonstrate this type of online-to-offline trend. However, one major exception to the trend is Facebook, which tends to demonstrate the opposite progression.

Facebook is a computer-mediated Social Networking System that has become one of the most popular means of communication in North America. Launched in 2004, Facebook had an estimated 1.2 million users in 2006 (Needham and Company as cited in Spitzberg, 2006) which grew to 21 million members in 2007 (Needham and Company as cited in Ellison et al., 2007). The initial purpose of Facebook was to allow university students to create and maintain social ties which were relevant to the university experience (Ellison et al., 2007). This goal appears to be met. Ellison and colleagues (2007) reported that 94\% of undergraduate students were Facebook users, spending 10-30 min online each day communicating with their "Friends List" of 150-200 people. Perhaps most interesting, the majority of these "Facebook Friends" were individuals known from the offline world; in other words, Facebook was not used as a tool to meet new people online

Despite the explosive growth in the number of Facebook users, research investigating Facebook has not increased proportionally. Moreover, as Ellison and colleagues (2007) note, much of the research which currently exists investigates identity presentation and privacy concerns. Considering the types of information which are part of a Facebook profile and the fact that the majority of Facebook contacts are known from the offline world, it does not appear that Facebook users are primarily concerned with privacy. In fact, most users of Facebook provide information in their profile, such as their high school, which encourages previously known friends and acquaintances to find them (Ellison et al., 2007).

With these behaviors in mind, there is reason to believe that more than identity presentation influences the use of Facebook. For example, personality characteristics such as Introversion and Extraversion have been found to play a significant role in other online communication experiences (e.g., Butt \& Phillips, 2008; Kraut et al., 2002).

\subsection{Personality factors}

One means of categorizing personality influences is in the context of the Five-Factor Model. The FiveFactor Model (FFM) divides personality into a series of five dimensional traits (McCrae, 1992). The first trait, Neuroticism, reflects a person's tendency to experience psychological distress and high levels of the trait are associated with a sensitivity to threat. Extraversion, the second trait, reflects a person's tendency to be sociable and able to experience positive emotions. The third factor, Openness to Experience, represents an individual's willingness to consider alternative approaches, be intellectually 
curious and enjoy artistic pursuits. Agreeableness, as the fourth factor, is another aspect of interpersonal behavior, reflecting a tendency to be trusting, sympathetic and cooperative. The fifth dimension, Conscientiousness, reflects the degree to which an individual is organized, diligent and scrupulous.

In addition to predicting general online behaviors, these five traits have also been found to be associated with certain Computer Mediated Communication (CMC) activities. For example, Butt and Phillips (2008) described how those who were high on the trait of Neuroticism were likely to use the Internet to avoid loneliness. Likewise, in a study of online activity including chat rooms, discussion boards and instant messaging, Swickert, Hittner, Harris, and Herring (2002) found that individuals who were high on Neuroticism reported the lowest levels of perceived social support. These more recent findings reflect work by Wolfradt and Doll (2001) which found that when combined with high levels of social interests, those who were high on Neuroticism demonstrated a strong interest in using the Internet for communication. Moreover, in anonymous forms of online communication such as chat rooms, it has been observed that individuals high on the trait of Neuroticism were more likely to post accurate personal information on their profiles (Amichai-Hamburger, Wainpel, \& Fox, 2002). This style of posting information is likely intended bolster psychological support (Mantovani, 2001) that is otherwise missing for these psychologically vulnerable individuals.

Extraversion is another trait that has been shown to be associated with online use. Amichai-Hamburger and colleagues (2002) argued that personality constructs are associated with the location in which a person places their true identity; those who are introverted have a tendency to view their real self as being located online, while more extraverted individuals are likely to locate their true identity offline. Because they are more likely to locate their true self online (Amichai-Hamburger et al., 2002), individuals who are low on the trait of Extraversion (i.e., are introverted) are more likely to utilize technology such as an SNS for their communication needs. However, technologies like Facebook may actually disadvantage an introvert because they rely on the types of offline relationships that an extravert is more likely to develop. These challenges are even more pronounced for introverts who are low on Agreeableness (Landers \& Lounsbury, 2006). According to Landers and Lounsbury (2006) a low score on the trait of Agreeableness was associated with individuals who were unpleasant to be around because they did not possess the types of social graces that made their company desirable. Thus, an individual who is low on both Extraversion and Agreeableness is likely to have significant diffi- culty in forming offline friendships and, therefore, is likely to have fewer friends who can be added to an SNS like Facebook. This supposition is reinforced by Butt and Phillips (2008) who noted that those who were low in Agreeableness are the ones who were most likely to receive cellular phone calls in public places. Not only did these individuals lack the etiquette to excuse themselves to talk, but they were more likely to be called on the phone, as others prefer to avoid engaging them face-to-face (Butt \& Phillips, 2008)

Openness to Experience is the personality factor most likely to be associated with trying out new methods of communication, or using an SNS to seek out new and novel experiences (Butt \& Phillips, 2008). The role of Openness to Experience in Facebook use is less clear, however, Facebook has become a relatively mainstream communication tool for university students (Ellison et al., 2007) and thus may no longer be a "unique" experience. 
Conscientiousness has previously been shown to be negatively related to the use of the Internet and other forms of CMC (Butt \& Phillips, 2008; Swickert et al., 2002). This trend is likely given that those who are high on the trait of Conscientiousness are dutiful and responsible in their tasks, and therefore those scoring high on the trait of Conscientiousness are more likely to avoid CMC tools which may serve as procrastination or distraction tools from their daily tasks. However, there is little existing research for Conscientiousness in terms of an offline-to-online SNS like Facebook.

\subsection{Competency and familiarity}

Despite its potential influence, personality of the user is not the only factor likely to impact the use of the Internet for communication. One of the major determinants of technology use is competency (Spitzberg, 2006). Over time and with appropriate experience, individuals may eventually view communication technology as invisible; that is, they communicate without thinking about how they are communicating (Lewis \& Fabos, 2005). For example, few individuals today would hesitate to pick up the telephone in order to communicate with a friend or family member as the phone has become an integrated and accepted piece of communication technology. However, adults might be more hesitant to communicate with that same individual if they were forced to utilize the texting feature of their cellular phone. Because texting is a less familiar technology, there is likely to be a significantly greater focus on how to communicate (i.e., how to form letters from a numerical keypad) and a lesser focus on what to communicate.

However, it is also important to realize that at some point, all communication technologies are foreign to the user. As such, it is necessary to take into consideration a person's motivation for communication (Spitzberg, 2006). In fact, Spitzberg argued that motivation actually appears before skill acquisition. This proposition seems valid in light of research by Bryant, Sanders-Jackson, and Smallwood (2006) which demonstrated that adolescents were quite willing to learn new communication technologies in order to maintain relationships with their peers outside of school.

\subsection{Present study}

By including personality factors and issues related to competency, the present research was designed to explore how personality characteristics and competency influenced the ways in which university students utilized Facebook for social purposes. In part, this research was intended to examine the trends of Facebook usage for a contemporary Canadian sample. In particular, we used self-report measures to examine key usage factors including the time spent online, the use of Facebook-specific communication functions (i.e., the Wall, personal messages) and Facebook group membership. Additionally, attitudes toward Facebook, the posting of personallyidentifying information and CMC competence were examined. Based on research discussed above and the nature of the personality characteristics we are examining, we developed the following hypotheses:

1. Because of their greater tendency to be sociable, it was hypothesized that individuals who scored higher on the trait of Extraversion would demonstrate more frequent Facebook use and greater use of Facebook features for communication, have more "Facebook Friends" and would belong to more Facebook groups. 
2. Because of their desire to seek online social support, it was expected that individuals who scored higher on the trait of Neuroticism would be more willing to share personally-identifying information on Facebook, spend more time on Facebook and be less likely to use private messages.

3. Because of their ability to engage in caring and meaningful interpersonal offline relationships, it was expected that individuals who scored higher on the trait of Agreeableness would have more "Facebook Friends" added to their profile.

4. Due to their tendency to be curious and desire to explore new activities, individuals who scored higher on the trait of Openness to Experience were expected to be more willing to use Facebook as a communication tool and to use a greater number of features, resulting in greater knowledge of Facebook features.

5. Because of their tendency to meet deadlines and be responsible with obligations, it was expected that individuals who scored higher on the trait of Conscientiousness would demonstrate more limited Facebook activities.

6. We also asked the following research question based on research by Spitzberg (2006): how would competency and familiarity factors be related to the functions of Facebook that participants utilize.

\section{Method}

Ninety-seven students at a university in Southwestern Ontario participated in the present study. The sample was comprised of 15 men and 82 women, having an average age of 21.69 years $(S D=5.40)$. Students were compensated with partial course credit for their participation.

\subsection{Materials}

All study materials were posted online. The Facebook Questionnaire was a 28-item questionnaire developed by the authors (see Appendix A). It contained three categories of items assessing basic use of Facebook, attitudes associated with Facebook and the posting of personally-identifying information. Response alternatives ranged from nine-item multiple choice to yes/no depending on the nature of the item. Basic use items were devised to gather data on the frequency of use of functions that are common to the most basic Facebook profiles. Included in this list of basic functions were: the use of the Wall (a public forum where other Facebook users can post messages on one's Facebook profile); posting photos; sending private messages (which allows Facebook users to communicate with one another, in a manner accessible only through the Facebook server); the use of the "poke" function (which allows one Facebook user to indicate an interest or intent to speak with another Facebook user); participating in groups (online forums for which members with similar interests can join and discuss the topic of interest); posting of and participating in events (which, on Facebook, serve as indications of real world events); status changes (which allow a Facebook user to indicate what they are doing in the present 
moment when they change their status); and the use of comments (whereby a Facebook user can comment on their friends' posted material, such as photos).

Items related to attitudes toward Facebook were taken from Ellison and colleagues (2007) and supplemented with a single item added by the present authors. The posting of personally-identifying information was assessed by asking participants to indicate the whether they had posted sensitive personal information (e.g., phone number, mailing address).

Participants completed part of Spitzberg's (2006) measure of Computer Mediated Communication (CMC) Competence. The CMC Competence Measure used in this study was comprised of 13 items, each of which utilizes a five-point scale ranging from 1 (not at all true of me) to five (very true of me). This version of the measure produces three domains of competence: Motivation (e.g., "I look forward to sitting down at my computer to write to others"), Knowledge (e.g., "I am very familiar with how to communicate through e-mail and the Internet" or "I am never at a loss for something to say in CMC"), and Efficacy (e.g., "I feel completely capable of using almost all currently available CMCs"). Reliability for the three domains is acceptable (from $a=.73$ to $a=.90$ ) and each of the domains correlates with expected types of CMC behaviors (Bubas, 2006).

Participants completed the NEO-PI-R in order to assess personality along the Five-Factor Model domains. The NEO-PI-R is comprised of 240 questions, each of which utilizes a five-point scale ranging from 0 (strongly agree) to 4 (strongly disagree). The NEOPI-R demonstrates strong reliability and validity and the scale is frequently used in both personality and clinical research projects (Costa \& McCrae, 1992a, 1992b).

\subsection{Procedure}

Participants were recruited through the university's psychology participation pool and received bonus points for participating. After indicating an interest in the study, participants were sent an e-mail containing the study's URL as well as the necessary login credentials. Although the survey was hosted on the university's web server, it was not possible to access the study website without these credentials. Participants were also provided with an individual identification code which allowed them to return to their survey in case they were accidentally disconnected. The data presented here were part of a larger battery focused on correlates of CMC use. The total battery took approximately $60 \mathrm{~min}$ to $580 \mathrm{C}$. Ross et al. / Computers in Human Behavior 25 (2009) 578-586 complete. Participants were recruited over a two-week timeframe in February, 2008.

\section{Results}

Consistent with previous research (e.g., Ellison et al., 2007), 85\% of the participants in this study reported having a Facebook account, with the majority (79\%) reporting that they spent between 10 and 60 min on Facebook daily. Because of the large proportion of female participants in the study, it was not feasible to examine gender differences in terms of Facebook use or personality variables. 
In order to investigate personality features, groups were created by dividing each personality domain into equal thirds. The NEO-PIR T-score cutoffs for each personality domain are listed in Table 1. Only the upper and lower thirds were analyzed and all scores were within three standard deviations from the mean. Personality researchers have highlighted that one methodological challenge in personality research is that of small effect sizes (Butcher, Graham, \& Ben-Porath, 1995). Personality research that utilizes smaller sample sizes (e.g., due to convenience sampling) must employ statistics that are more sensitive to differences than would otherwise be the case. It is for this reason that we divided the personality dimensions into thirds. That is, we examined differences between those participants who scored in the highest third on a particular personality dimension and those who scored in the lowest third on that same dimension. Such a test allows for greater statistical sensitivity in searching for group differences, especially given our sample size. Furthermore, the sample used in the present study was not a clinical sample. Therefore, there is greater likelihood that the distribution of scores on the personality dimensions was restricted in range. Thus, by examining the highest and lowest third of each personality dimension, we are able to compare the "purer" forms of personality extremes that would be anticipated in a "normal" population. For consistency, the CMC Competency questionnaire was analyzed in a similar fashion. Cutoff scores for the CMC Competency measure can be found in Table 1. All scores were within three standard deviations of the mean.

Consistent with expectations, individuals in the high Extraversion group reported membership in significantly more groups $(M=14.81, S D=11.11)$ than individuals in the low Extraversion group $(M=$ $7.94, \mathrm{SD}=5.83), \mathrm{t}(42)=2.44, \mathrm{p}=.019, \mathrm{~d}=0.75$. Contrary to our expectation, however, Extraversion was not significantly related to number of "Facebook Friends", time spent online or use of the communicative Facebook features (e.g., frequency of Facebook status change).

Neuroticism was unrelated to the posting of personally-identifying information such as mailing address or phone number, nor was it related to the use of communicative features of Facebook. Exploratory analyses revealed that this trait was associated with preferred Facebook application such that individuals high in Neuroticism preferred using the Facebook Wall, whereas those low in Neuroticism preferred posting photos on their Facebook profile, v2 (4) $=9.54, p=.049$. Contrary to hypotheses 3 and 4, Agreeableness and Openness to Experience were unrelated to features of Facebook use.

Competency factors were also expected to impact Facebook use. Consistent with this expectation, it was found that those who were in the group high for CMC Motivation reported spending more time per day on Facebook $(M=3.04, S D=1.26)$ than those in the low group $(M=1.40, S D=0.83), t(36)=4.45, p<$ $.001, d=1.48$. This indicates that those in the high Motivation group typically spent 31-60 min per day on Facebook, while those in the low Motivation group typically spent 10 min per day or less on Facebook. CMC Motivation was also significantly related to the frequency with which individuals checked their own Wall. People in the highest third on the CMC Motivation scale checked their Wall more frequently $(M=7.96, S D=1.36)$ than those low on $C M C$ Motivation $(M=5.40, S D=2.80), t(36)=$ $3.77, p=.001, d=1.26$. This indicates that those in the high Motivation group typically checked their Wall once daily, while those in the low Motivation group typically checked their Wall approximately once monthly. CMC Motivation was not related to communicative features of Facebook use. 
In order to develop more robust indicators of use from the Facebook questionnaire, a factor analysis was conducted in order to extract factors that emerged. It was believed that this approach would yield data which was not accurately captured by the analysis of single items, especially regarding attitudes and style of Facebook use. A principal components factor analysis with varimax rotation was performed and two factors were extracted (factors and associated items are presented in Table 2). The first was labeled Attitudes $(a=85)$ and, as expected, was comprised of all the items borrowed from Ellison et al. (2007) in addition to the item composed by the authors (i.e., "How satisfied are you with Facebook, overall?"). The second factor, Online Sociability Functions $(a=.74)$, was composed of questions relating to the frequency with which individuals engaged in different Facebook activities (e.g., "how often do you send private messages").

To better understand the personality influences on the two domains from the Facebook questionnaire, two stepwise regressions were performed with the five personality domains as predictors. Personality variables were only found to predict the Online Sociability Functions factor from the Facebook questionnaire, $F(1,80)=5.26, p=.024$. As expected, higher levels of Openness to Experience $(b=.25)$ were associated with greater online sociability function use.

Analyses revealed that, consistent with hypothesis 4, Openness to Experience significantly predicted the knowledge factor from the CMC Competence measure, $F(1,95)=5.70, p=.019$. Contrary to earlier hypotheses, lower levels of Openness to Experience $(b=.24)$ were associated with greater knowledge about CMC.

\section{Discussion}

The purpose of the present study was to examine the influence of personality and competency factors on Facebook use. Consistent with previous research, our findings indicated that personality variables were associated with some aspects of Facebook use. For example, individuals high on the trait of Extraversion were found to belong to significantly more Facebook groups. Since extraverts are more likely to engage in social activities (Costa \& McCrae, 1992a, 1992b), it is reasonable to assume that these individuals maintain ties to their groups through Facebook. Surprisingly, levels of Extraversion were not associated with number of "Facebook Friends," or communicative functions of Facebook. These results suggest that although those high on the trait of Extraversion may utilize Facebook as a social tool, they do not use Facebook as an alternative to social activities. This is consistent with research by Amiel and Sargent (2004) who found that extraverts do not use the Internet as a substitute for real-world interactions, but rather are more likely to use forms of $\mathrm{CMC}$ to voice their own opinions, conduct research and share music with others. Since Facebook does not allow the same kind of immediate communication as other forms of CMC such as instant messaging, it may be that extraverts find Facebook to be lacking in the type of immediate social contact they desire.

Those high on the trait of Neuroticism reported that the Wall was their favourite Facebook component, whereas those low on Neuroticism preferred photos. One possible explanation for this finding can be found in research by Butt and Phillips (2008). These authors observed that Neuroticism plays a role in information control, such that those high in the trait of Neuroticism are more likely to control what information is shared. With a Wall posting, an individual has a great deal of time to consider his or her response and is capable of limiting the amount of extraneous information presented as Wall posts are 
entirely textual and can be deleted afterwards. Photos, on the other hand, may inadvertently convey information about emotional states or geographical location, which may seem threatening to an individual's well being and may make them too threatening for individuals high in Neuroticism.

Openness to Experience was found to be related to online sociability and CMC knowledge. Specifically, a willingness to consider alternative methods of communication was found to be important in Facebook use. As expected, higher levels of Openness to Experience were associated with a greater tendency to be sociable through Facebook. Considering that those who are high on the trait of Openness to Experience are more likely to have a wide variety of interests and a willingness to pursue those interests through unusual means (Butt \& Phillips, 2008), the ability to use Facebook tools such as commenting and Walls would seem to be a natural fit for those who are inherently curious. Thus, it is somewhat puzzling that high trait levels of Openness to Experience was also associated with lower levels of CMC knowledge. One possible explanation for this finding is that because of their broad interests, people high in Openness to Experience have greater difficulty in trying to communicate with others through forms of $\mathrm{CMC}$ because their interests do not translate well. In other words, it may be that their variable interests require more description and explanation (i.e., facial cues, voice tone or nonverbal signals) than are readily provided through an inherently impoverished communication medium (Walther, 2006).

Alternatively, it may be that those who have high levels of Openness to Experience are more interested in trying new things than they are in trying to figure out how things work. In such a case, an individual would readily use the new functions in Facebook because of curiosity, but might be unable to troubleshoot a problem with e-mail because s/he has never taken the time to fully understand the system.

We anticipated that more agreeable individuals would have more online contact, but the results did not support this hypothesis. Additionally, we expected that Conscientiousness would be negatively related to Facebook in order to balance academic pursuits and requirements, but this was not a significant factor in any of the analyses. As such, both of these factors warrant attention in future research.

Consistent with Spitzberg's (2006) observation that motivation is one of the most important precursors to $\mathrm{CMC}$ use, the Motivation domain from the CMC Competence measure was associated with the amount of time an individual spent on Facebook each day, as well as the number of times that individual checked his/her Wall. However, this dimension of motivation was not associated with any particular personality variable. Thus, it would appear that motivation and competence can have an important bearing on online activities, independently of broader personality structures. This is an important consideration as motives may be more easily addressed than personality factors in trying to alter the amount of time spent online. This may have implications for treatment or clinical interventions. Tables

One of the most surprising outcomes from the present study was the relatively few significant findings in relation to the personality variables. Perhaps because Facebook represents a new offline-to-online Social Networking System, some of the predictions made from previous findings did not materialize. However, the fact that personality factors were not as influential as expected is similar to results obtained by Swickert and colleagues (2002). Swickert and colleagues also investigated online activities in a more fine-grained way than other research. Thus, instead of using global measures of use, the present 
research broke online activity down into specific activities. This suggests that personality defined by the Five-Factor approach may be too broad and not be the best way to understand specific Internet behaviors. For example, it may be that other more specific personality characteristics not defined by the Five-Factor Model such as narcissism or other traits such as shyness (e.g., Orr et al., in press) are more influential in activities related to Facebook use. It may also be that motivational factors such as desire for communication, seeking of social support and entertainment value may be more useful in understanding Facebook use than the ones we selected. These motivating factors appear to be independent of the Five-Factor approach to personality, yet are likely influential in the decision to use forms of CMC such as Facebook.

\section{References}

Amichai-Hamburger, Y., Wainpel, G., \& Fox, S. (2002). On the Internet no one knows I'm an introvert: Extroversion, introversion, and Internet interaction. CyberPsychology \& Behavior, 5(2), 125-128.

Amiel, T., \& Sargent, S. L. (2004). Individual differences in Internet usage motives. Computers in Human Behavior, 20(6), 711-726.

Bargh, J. A., \& McKenna, K. Y. A. (2004). The Internet and social life. Annual Review of Psychology, 55, 573-590.

Bryant, J. A., Sanders-Jackson, A., \& Smallwood, A. M. K. (2006). IMing, text messaging, and adolescent social networks. Journal of Computer-Mediated Communication, 11(2), 577-592.

Bubas, G. (2006). Competence in computer-mediated communication: An evaluation and potential uses of a self-assessment measure. International Communication Association Conference (pp. 1-38). Dresden, Germany.

Butcher, J. N., Graham, J. R., \& Ben-Porath, Y. S. (1995). Methodological problems and issues in MMPI-I, MMPI-2, and MMPI-A research. Psychological Assessment, 7(3), 320-329.

Butt, S., \& Phillips, J. G. (2008). Personality and self reported mobile phone use. Computers in Human Behavior, 24(2), 346-360.

Costa, P. T., \& McCrae, R. R. (1992a). Revised NEO personality inventory (NEO-PI-R) and the NEO FiveFactor inventory (NEO-FFI): Professional manual. Odessa, FL: Psychological Assessment Resources Inc.

Costa, P. T., \& McCrae, R. R. (1992b). Normal personality assessment in clinical practice: The NEO personality inventory. Psychological Assessment, 4(1), 5-13. 
Ellison, N. B., Steinfield, C., \& Lampe, C. (2007). The benefits of Facebook "friends:" Social capital and college students' use of online social network sites. Journal of Computer-Mediated Communication, 12(4), 1143-1168.

Goldberg, L. R., \& Rosolack, T. K. (1994). The Big Five factor structure as an integrative framework: An empirical comparison with Eysenck's P-E-N model. In C. F. Halverson, G. A. Kohnstamm, \& R. P. Martin (Eds.), The developing structure of temperament and personality from infancy to adulthood. England: Lawrence Erlbaum Associates.

Kraut, R., Kiesler, S., Boneva, B., Cummings, J., Helgeson, V., \& Crawford, A. (2002). Internet paradox revisited. Journal of Social Issues, 58(1), 49-74.

Landers, R. N., \& Lounsbury, J. W. (2006). An investigation of Big Five and narrow personality traits in relation to Internet usage. Computers in Human Behavior, 22, 283-293.

Lewis, C., \& Fabos, B. (2005). Instant messaging, literacies, and social identities. Reading Research Quarterly, 40(4), 470-501.

Mantovani, G. (2001). The psychological construction of the Internet from information foraging to social gathering to cultural mediation. CyberPsychology and Behavior, 4, 47-56.

McCrae, R. R. (1992). The five-factor model: Issues and applications [Special issue]. Journal of Personality, 60(2).

McKenna, Katelyn Y.A., Green,A. S.,\& Glenson,Marci E. J. (2002). Relationship formation on the Internet: What's the big attraction? Journal of Social Issues, 58(1), 9-31.

Orr, E. S., Sisic, M., Ross, C., Simmering, M. G., Arseneault, J. M., \& Orr, R. (in press). The influence of shyness on the use of Facebook in an undergraduate sample. CyberPsychology and Behaviour

Spitzberg, G. H. (2006). Preliminary development of a model and a measure of computer-mediated communication (CMC) competence. Journal of ComputerMediated Communication, 11, 629666.

Swickert, R. J., Hittner, J. B., Harris, J. L., \& Herring, J. A. (2002). Relationships among Internet use, personality, and social support. Computers in Human Behavior, 18(4), 437-451.

Tidwell, L. C., \& Walther, J. B. (2002). Computer-mediated communication effects on disclosure, impressions, and interpersonal evaluations: Getting to know one another a bit at a time. Human Communication Research, 28(3), 317-348.

Walther, J. B. (2006). Nonverbal dynamics in computer-mediated communication, or:(and the net:('s with you, :) and you:) alone. Thousand Oaks, CA, US: Sage Publications, Inc. 
Wolfradt, U., \& Doll, J. (2001). Motives of adolescents to use the Internet as a function of personality traits, personal and social factors. Journal of Educational Computing Research, 24(1), 13-27.

Tables

Table 1

Cutoff T-scores for NEO-PI-R and CMC Competency measure.

\begin{tabular}{lcc}
\hline & Low cutoff & High cutoff \\
\hline$N E O-P I-R$ & & \\
Neuroticism & 51 & 59 \\
Extraversion & 47 & 57 \\
Openness & 47 & 56 \\
Agreeableness & 36 & 47 \\
Conscientiousness & 41 & 50 \\
CMC competence measure & & \\
Knowledge & 18 & 21 \\
Motivation & 13 & 16 \\
Efficacy & 9 & 11 \\
\hline
\end{tabular}


Table 2

Factors from Facebook measure.

Attitudes

"Facebook is part of my everyday activity"

"I am proud to tell people I am on Facebook"

"I dedicate part of my daily schedule to Facebook"

"I feel out of touch when I haven't logged on to Facebook in a while"

"I feel I am part of the Facebook community"

"I would be sad if Facebook shut down"

"How satisfied are you with Facebook?"

Online sociability

"How often do you use Facebook during lectures?"

"How often do you comment on others' photos?"

"How often do you post on others' walls?"

"How often do you check your own wall?"

"How often do you send private messages?" 